PREPARED FOR THE U.S. DEPARTMENT OF ENERGY, UNDER CONTRACT DE-AC02-76CH03073

PPPL-3848

PPPL-3848

UC-70

Shape Optimization for DIII-D Advanced Tokamak Plasmas

by

C.E. Kessel, J.R. Ferron, C.M. Greenfield,

J.E. Menard, and T.S. Taylor

July 2003

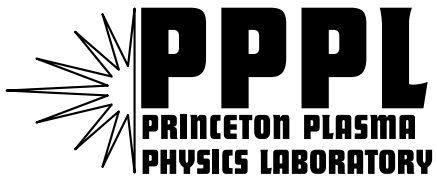

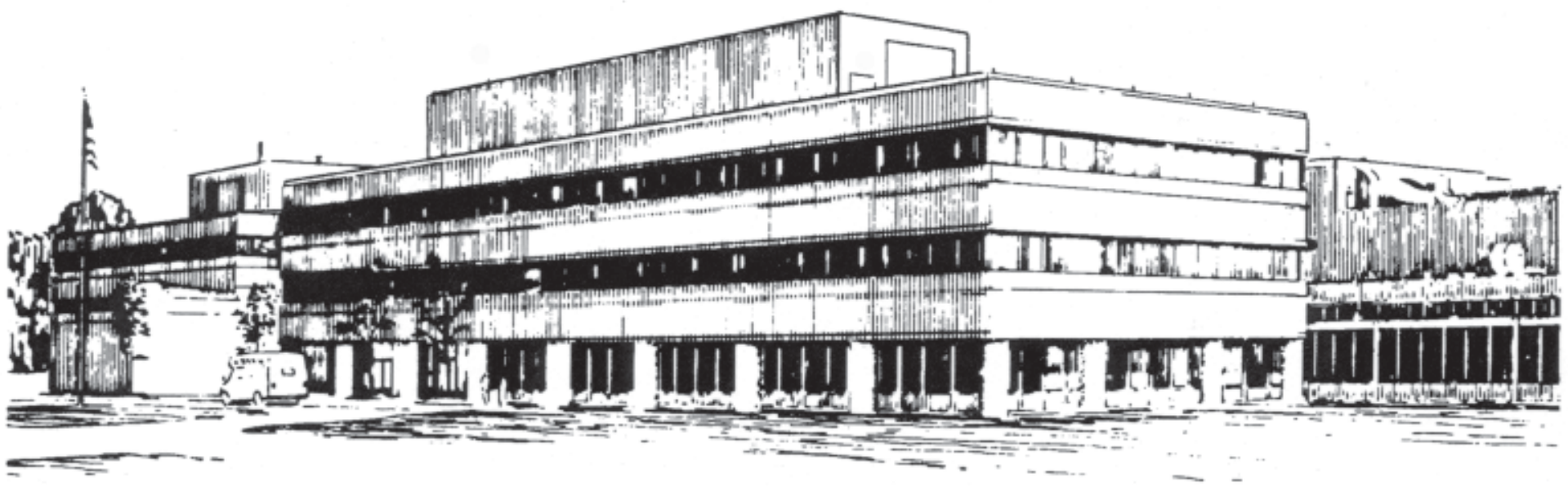

PRINCETON PLASMA PHYSICS LABORATORY PRINCETON UNIVERSITY, PRINCETON, NEW JERSEY 


\section{PPPL Reports Disclaimer}

This report was prepared as an account of work sponsored by an agency of the United States Government. Neither the United States Government nor any agency thereof, nor any of their employees, makes any warranty, express or implied, or assumes any legal liability or responsibility for the accuracy, completeness, or usefulness of any information, apparatus, product, or process disclosed, or represents that its use would not infringe privately owned rights. Reference herein to any specific commercial product, process, or service by trade name, trademark, manufacturer, or otherwise, does not necessarily constitute or imply its endorsement, recommendation, or favoring by the United States Government or any agency thereof. The views and opinions of authors expressed herein do not necessarily state or reflect those of the United States Government or any agency thereof.

\section{Availability}

This report is posted on the U.S. Department of Energy's Princeton Plasma Physics Laboratory Publications and Reports web site in Fiscal Year 2003. The home page for PPPL Reports and Publications is: http://www.pppl.gov/pub_report/

DOE and DOE Contractors can obtain copies of this report from:

U.S. Department of Energy

Office of Scientific and Technical Information

DOE Technical Information Services (DTIS)

P.O. Box 62

Oak Ridge, TN 37831

Telephone: (865) 576-8401

Fax: (865) 576-5728

Email: reports@adonis.osti.gov

This report is available to the general public from:

National Technical Information Service

U.S. Department of Commerce

5285 Port Royal Road

Springfield, VA 22161

Telephone: $1-800-553-6847$ or

(703) $605-6000$

Fax: (703) 321-8547

Internet: http://www.ntis.gov/ordering.htm 


\title{
Shape Optimization for DIII-D Advanced Tokamak Plasmas
}

\author{
C. E. Kessel ${ }^{1}$, J. R. Ferron ${ }^{2}$, C. M. Greenfield ${ }^{2}$, J. E. Menard ${ }^{1}$, and T. S. Taylor ${ }^{2}$ \\ ${ }^{1}$ Princeton Plasma Physics Laboratory, P.O. Box 451, Princeton, NJ 08543 \\ ${ }^{2}$ General Atomics, 3550 General Atomics Ct., San Diego, CA 92121
}

The advanced tokamak program on DIII-D is targeting the full integration of high $\beta$ and high bootstrap/non-inductive current fraction for long pulse lengths, and the high confinement consistent with these features. Central to achieving these simultaneously is access to the highest ideal $\beta$ limits possible to maximize the headroom for experimental operation with RWM control. A study of the ideal MHD stability is done for plasmas modeled after DIII-D advanced tokamak plasmas, varying the plasma elongation, triangularity, and outboard squareness. The highest $\beta_{\mathrm{N}}$ limits reach 6-7 for the $n=1$ kink mode for all $\kappa$ and $\zeta_{\text {o }}$ values and $\delta=0.8$.

\section{Equilibrium and Stability Analysis}

In order to examine the benefits of divertor modifications and establish the maximum $\beta_{\mathrm{N}}$ headroom for advanced tokamak plasmas in DIII-D, equilibrium and ideal MHD stability calculations were done varying the elongation, triangularity and outer squareness. Free-boundary equilibria for diverted plasmas, within the DIII-D PF coil and vacuum vessel/limiter boundary, were done to determine the fixed boundary shape parameters that best approximates the actual shapes. Only up-down symmetric double null plasmas were examined. The fixed boundary plasma shapes, to be used in the stability studies, were described by the following,

$$
\begin{aligned}
& R=R_{o}+a \cos \left(\theta+\sin ^{-1} \delta \sin \theta\right) \\
& Z=\kappa a \sin \left(\theta+\zeta_{o, i} \sin 2 \theta\right)
\end{aligned}
$$

where $\delta, \kappa, \zeta_{0}$, and $\zeta_{\mathrm{i}}$ are the plasma triangularity, elongation, outer squareness, and inner squareness, respectively. The free-boundary studies indicated that the inner squareness should be fixed at approximately -0.25 to best approximate the plasma boundary on the inboard side and near the x-point. The inner squareness is applied for poloidal angles between 90 and 180 degrees, measured from the outboard midplane, and the outer squareness is applied from 0 to 90 degrees. The plasma major radius is fixed at $1.688 \mathrm{~m}$, the minor radius at $0.587 \mathrm{~m}$, and the toroidal field is $1.85 \mathrm{~T}$.

The current profiles in the advanced tokamak plasmas produced in DIII-D experiments have contributions from the NBI, EC, bootstrap, and inductive current drive. For this study the current profile is taken as fully non-inductive, with the NBCD at $300 \mathrm{kA}$ and ECCD at $120 \mathrm{kA}$, and their profiles fixed to approximate those in AT experiments[1]. The bootstrap current is then self-consistently determined in the equilibrium calculation using the Sauter single ion formulation[2]. An example of one of these equilibria is shown in Fig.1.

The density profile is fixed and the temperature profile is determined as the ratio of pressure over density. The model pressure profile is fixed for these studies, with core and pedestal components, the pedestal comprising $10 \%$ of the peak pressure value. 
The pedestal was modeled with a hyperbolic tangent term and was placed at a normalized poloidal flux of 0.875 with a width in poloidal flux of 0.05

$$
p(\psi)=p_{o}\left[0.6\left(1-\widehat{\psi}^{1.5}\right)^{1.5}+0.3(1-\widehat{\psi})^{3.5}+0.1 \tanh \left(\widehat{\psi}_{o}, \Delta \psi\right)\right]
$$

The pressure profile is then scaled to generate various $\beta_{\mathrm{N}}$ values. The plasma current floats since the bootstrap current is being determined consistently with the equilibrium. The plasma current ranges in values from 0.9 to $2.0 \mathrm{MA}$.

The fixed boundary flux coordinate equilibrium code JSOLVER[3] is used to produce the equilibrium. The input functions are the plasma pressure and the parallel current density from external sources (NB and EC). The grid used is 257 flux surfaces by 257 equal arc theta points, and up-down symmetry is used since only DN plasmas are examined. The high-n ballooning stability is evaluated with BALMSC[4]. The low-n kink stability is examined with PEST2[5], and a conforming ideal wall is assumed at $1.5 \mathrm{a}$ measured from the plasma center. The toroidal mode numbers $n=1-3$ are evaluated.

\section{$\underline{\text { Results and Discussion }}$}

The plasma shaping ranges examined were $1.7 \leq \kappa \leq 2.1,0.5 \leq \delta \leq 0.8$, and $0.0 \leq \zeta_{\mathrm{o}} \leq$ 0.2. Shown in Fig. 2 are the results for $n=\infty$ ballooning and $n=1$ kink modes. The $\mathrm{n}=1$ kink mode limits increase significantly with triangularity, reaching $\beta_{\mathrm{N}}$ 's of 6-7. The highest values are obtained with the lowest outboard squareness, as this tends to strengthen the magnetic shear near the plasma edge. Higher plasma elongation in combination with low outer squareness at lower triangularity, and higher outer squareness at higher triangularity maximize the ballooning stability limits. The $n=2$ and $n=3$ modes set lower $\beta_{N}$ limits than for $n=1$ over the entire range of shapes. This reflects the theoretical result that with wall stabilization, $n=1$ obtains the highest $\beta_{N}$, while $n=2,3$ and possibly higher values set progressively lower limits[6]. This effect normally turns around as $\mathrm{n}$ increases, with the wall no longer benefiting higher mode numbers. Their behavior is similar to $n=1$, in that these modes prefer higher elongation with high triangularity and low squareness which maximizes the magnetic shear near the plasma edge.

The interpretation of ideal MHD instabilities is not always clearly understood. Since the model is linear it does not describe how the unstable modes will manifest themselves, for example, as a disruption or as enhanced transport. Experimentally high-n ballooning modes do not result in disruptions, although high quality equilibrium reconstructions suggest that in the core the plasma pressure gradient does not exceed the ballooning critical gradient by any significant amount. In addition, the ballooning instability near the edge associated with the pedestal pressure gradient, is considered a primary candidate for ELMs, which do not disrupt the plasma. On the other hand, the $n=1$ external kink mode, or the resistive wall mode in the presence of a conducting wall, is disruptive.

The $\mathrm{n}=2$ and 3 modes fall in between, and are not found to be the cause of disruptions. Modes with toroidal numbers of 4 up to high values have been classified as peeling modes due to their compressed mode structure at the plasma boundary. It 
is possible that the $n=2$ and 3 modes are peeling modes, although their mode structure appears to extend deeper into the plasma. An interesting observation in ref.[7] is that these modes may ultimately cause neoclassical tearing modes, rather than manifest themselves as large ideal disruptive instabilities. This is due to a rapid positive increase in $\Delta^{\prime}$ as the ideal mode begins to grow, initiating a classical tearing mode. This provides the seed island for a neoclassical tearing mode to grow in a high $\beta$ plasma. This would indicate that comparing plasma shapes that have high $n=2$ and 3 $\beta_{\mathrm{N}}$ limits to those that have low values, to look for a systematic sensitivity to NTM's.

The experiment routinely obtains $\beta_{\mathrm{N}}$ in the range of 3.1-3.5 in AT plasmas, depending on the pressure peaking and plasma shape. The peak to volume average for this stability analysis is 2.3 . Very recent shaping experiments[8] on DIII-D indicate 10$15 \%$ inprovements in the $\beta_{\mathrm{N}}$ when the elongation and triangularity increase together from 1.8 and 0.5 to 2.0 and 0.8 , respectively at fixed $\mathrm{I} / \mathrm{aB}, \mathrm{q}_{\mathrm{Min}}$, and pressure peaking.

In summary, a shape study has been performed to examine the impact of plasma elongation, triangularity and outer squareness on the ideal MHD stability of fully noninductive plasmas modeled after DIII-D advanced tokamak plasmas. The results indicate that higher elongation is uniformly beneficial to all modes, while the combination of triangularity and outer squareness vary between low-n kink modes that prefer high edge magnetic shear and high-n ballooning modes that prefer the opposite. Although the $n=1$ mode can access high $\beta_{\mathrm{N}}$ limits in the presence of a wall, the $n=2$ and 3 modes appear to be setting lower limits. However, how they manifest themselves in limiting access to high $\beta$ in the plasma is not understood.
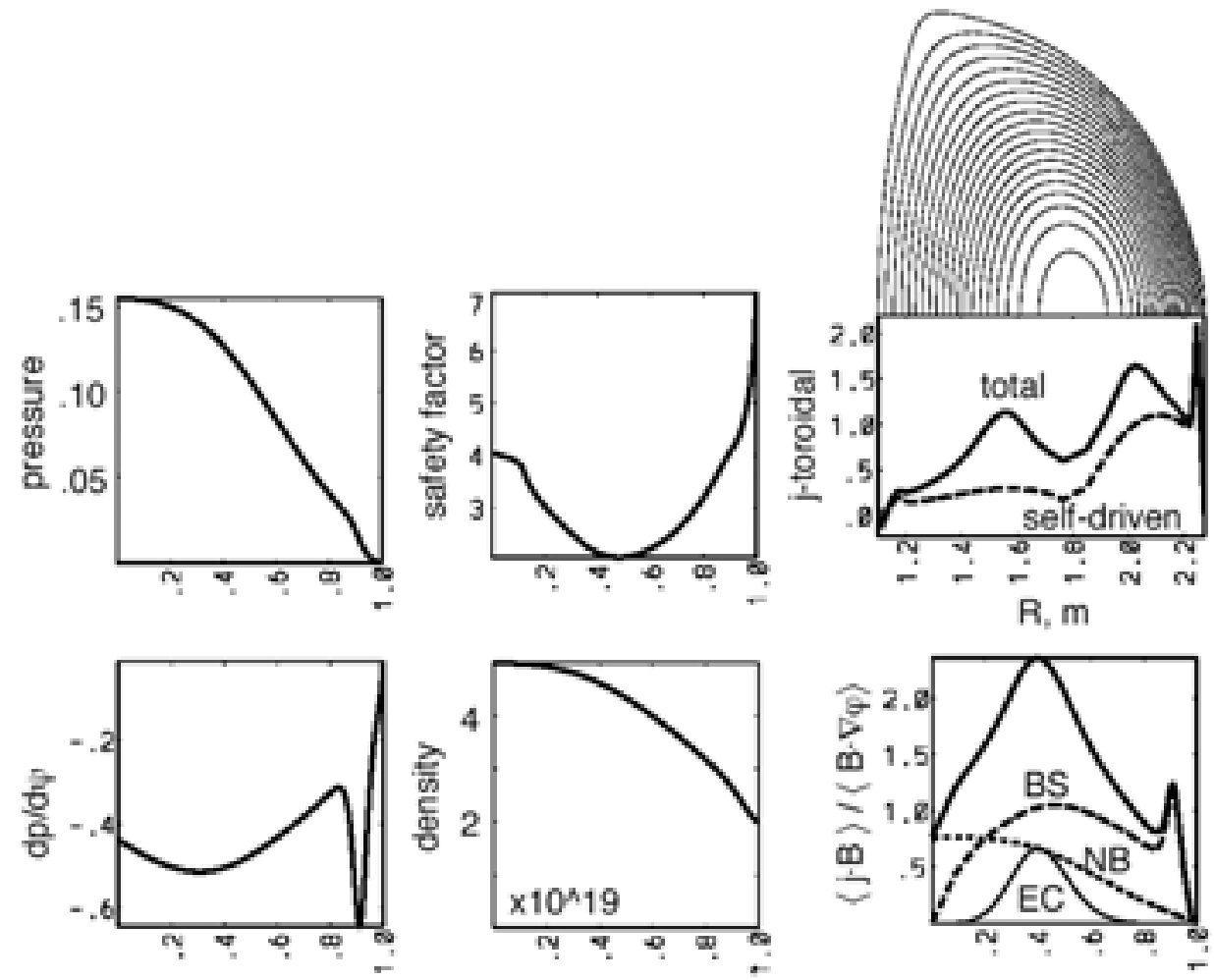

Figure 1. An example of the model DIII-D AT plasmas in this study showing the equilibrium profiles and plasma shape, this particular plasma reached a stable $\beta_{\mathrm{N}}$ of 3.65 . 

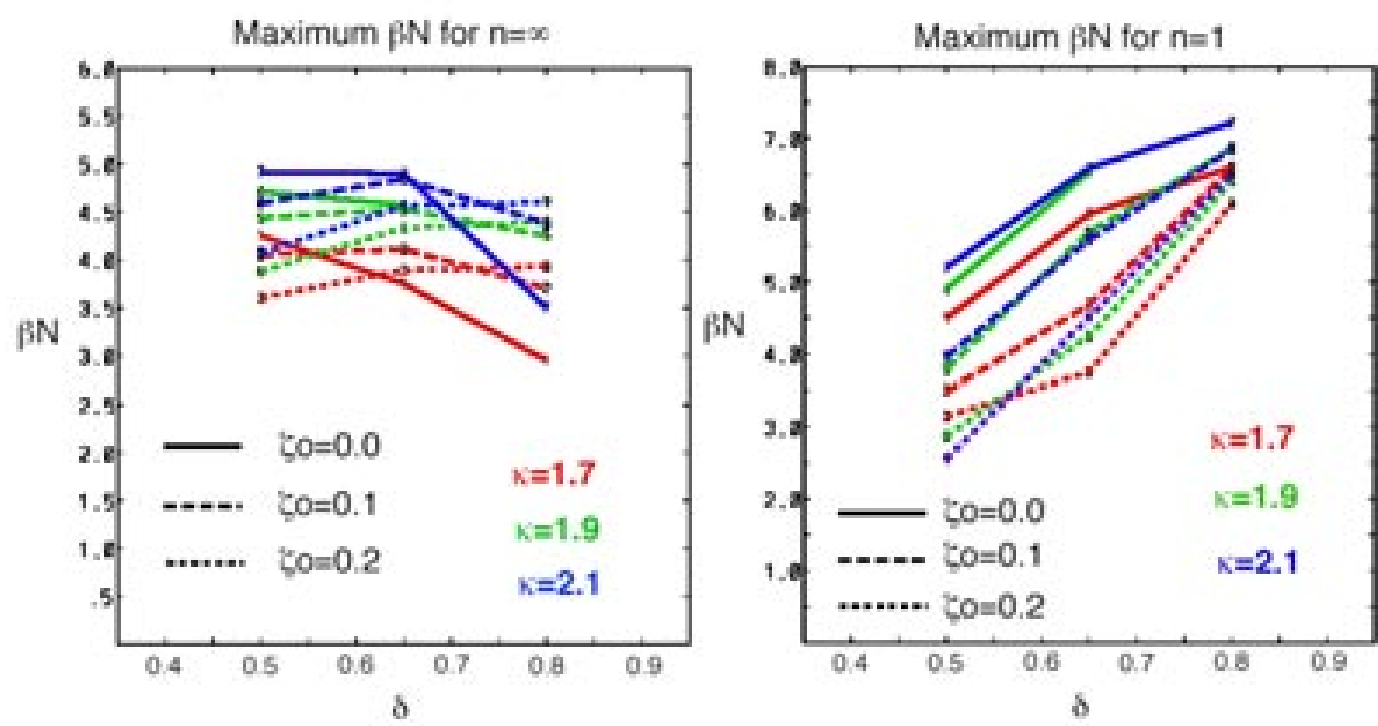

Figure 2. Maximum $\beta_{\mathrm{N}}$ for high-n ballooning and $\mathrm{n}=1$ external kink modes as a function of plasma elongation, triangularity, and outboard squareness.
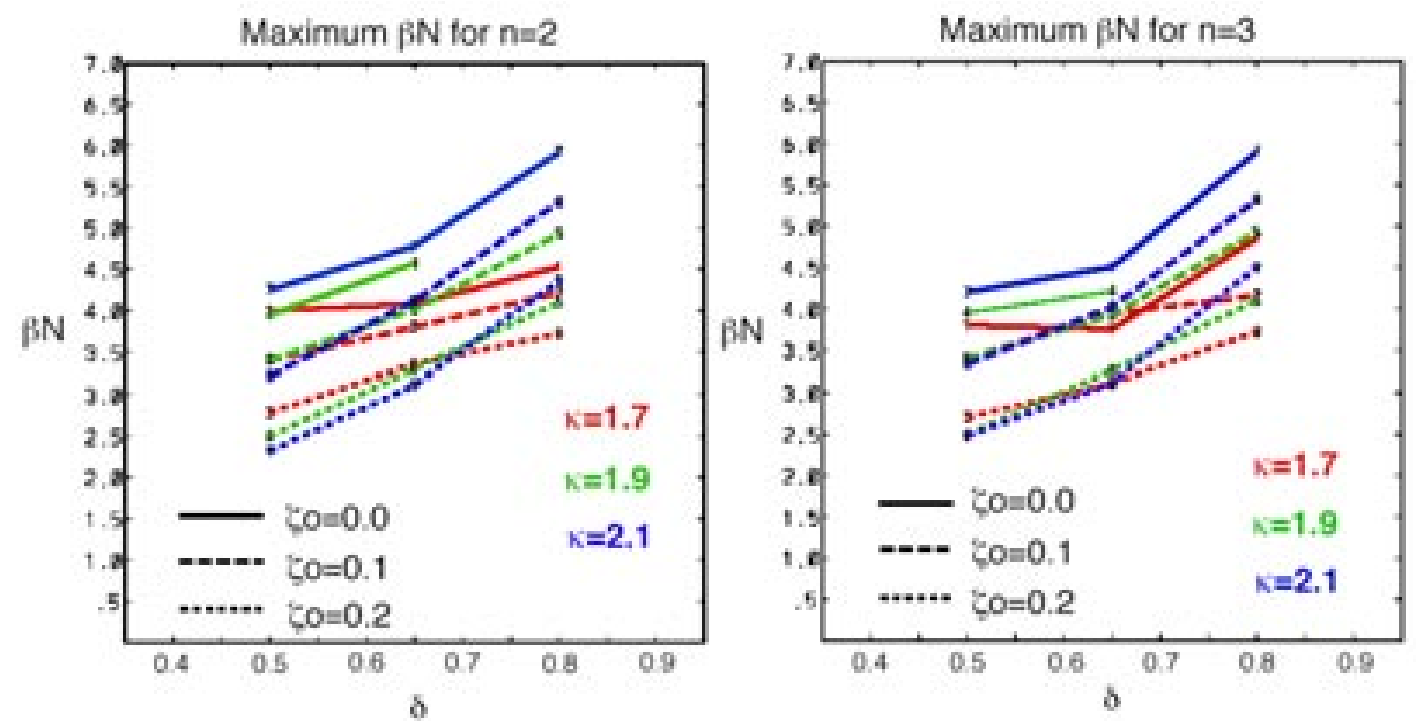

Figure 3. Maximum $\beta_{\mathrm{N}}$ for $\mathrm{n}=2$ and 3 external kink modes as a function of plasma elongation, triangularity, and outboard squareness.

Work supported by U.S. DOE contracts DE-AC02-76CH03073 and DE-AC0399ER54463

References

[1] M. Murakami, et al., Phys. Plasmas, 10, 1691, (2003).

[2] O. Sauter, et al., Phys. Plasmas, 6, 2834, (1999).

[3] J. DeLucia, et al., J. Comp. Phys., 37, 183, (1981).

[4] J. M. Greene and M. S. Chance, Nucl. Fusion, 21, 453, (1981).

[5] R. C. Grimm, et al., J. Comp. Phys., 49, 94, (1983).

[6] C. Kessel, et al., Phys. Rev. Lett., 72, 1212, (1994).

[7] D. Brennan, et al., $28^{\text {th }}$ EPS Conference on Plas. Physics in Cont. Fusion, 2001. [8] J. Menard, private communication. 


\section{External Distribution}

Plasma Research Laboratory, Australian National University, Australia

Professor I.R. Jones, Flinders University, Australia

Professor João Canalle, Instituto de Fisica DEQ/IF - UERJ, Brazil

Mr. Gerson O. Ludwig, Instituto Nacional de Pesquisas, Brazil

Dr. P.H. Sakanaka, Instituto Fisica, Brazil

The Librarian, Culham Laboratory, England

Mrs. S.A. Hutchinson, JET Library, England

Professor M.N. Bussac, Ecole Polytechnique, France

Librarian, Max-Planck-Institut für Plasmaphysik, Germany

Jolan Moldvai, Reports Library, Hungarian Academy of Sciences, Central Research Institute for Physics, Hungary

Dr. P. Kaw, Institute for Plasma Research, India

Ms. P.J. Pathak, Librarian, Institute for Plasma Research, India

Ms. Clelia De Palo, Associazione EURATOM-ENEA, Italy

Dr. G. Grosso, Instituto di Fisica del Plasma, Italy

Librarian, Naka Fusion Research Establishment, JAERI, Japan

Library, Laboratory for Complex Energy Processes, Institute for Advanced Study, Kyoto University, Japan

Research Information Center, National Institute for Fusion Science, Japan

Dr. O. Mitarai, Kyushu Tokai University, Japan

Dr. Jiangang Li, Institute of Plasma Physics, Chinese Academy of Sciences, People's Republic of China

Professor Yuping Huo, School of Physical Science and Technology, People's Republic of China

Library, Academia Sinica, Institute of Plasma Physics, People's Republic of China

Librarian, Institute of Physics, Chinese Academy of Sciences, People's Republic of China

Dr. S. Mirnov, TRINITI, Troitsk, Russian Federation, Russia

Dr. V.S. Strelkov, Kurchatov Institute, Russian Federation, Russia

Professor Peter Lukac, Katedra Fyziky Plazmy MFF UK, Mlynska dolina F-2, Komenskeho Univerzita, SK-842 15 Bratislava, Slovakia

Dr. G.S. Lee, Korea Basic Science Institute, South Korea

Institute for Plasma Research, University of Maryland, USA

Librarian, Fusion Energy Division, Oak Ridge National Laboratory, USA

Librarian, Institute of Fusion Studies, University of Texas, USA

Librarian, Magnetic Fusion Program, Lawrence Livermore National Laboratory, USA

Library, General Atomics, USA

Plasma Physics Group, Fusion Energy Research Program, University of California at San Diego, USA

Plasma Physics Library, Columbia University, USA

Alkesh Punjabi, Center for Fusion Research and Training, Hampton University, USA

Dr. W.M. Stacey, Fusion Research Center, Georgia Institute of Technology, USA

Dr. John Willis, U.S. Department of Energy, Office of Fusion Energy Sciences, USA

Mr. Paul H. Wright, Indianapolis, Indiana, USA 
The Princeton Plasma Physics Laboratory is operated by Princeton University under contract with the U.S. Department of Energy.

\author{
Information Services \\ Princeton Plasma Physics Laboratory \\ P.O. Box 451 \\ Princeton, NJ 08543
}

Phone: 609-243-2750

Fax: 609-243-2751

e-mail: pppl_info@pppl.gov

Internet Address: http://www.pppl.gov 